\title{
A STUDY ON DIFFERENCE IN SHORT- TERM MEMORY IN HEALTHY MALES AND FEMALES OF KERALA
}

\author{
Sailesh Sai Kumar, George Jissa and J.K.Mukkadan
}

\begin{abstract}
Background and objectives: The studies on difference in short- term memory in healthy males and females of Kerala of Kerala are inadequate. Therefore the present study was undertaken to observe whether there is a difference in short-term memory of males and females of Kerala and to create awareness among the healthy male and female to improve the quality of life.

Methodology: The present study was performed in forty healthy males and females of Kerala with mean age $23+/-5$. our study we have used a free- recall task of words, numbers and pictures in six sessions. We have asked the subjects to recall the displayed words, numbers and pictures. Numbers of the correct items recalled were measured. The analysis of data is done by SPSS 20.0.

Results: The results of the present study suggests that males are having more short-term memory for numbers which is statistically significant and females are having more short-term memory for words which is statistically significant and slightly more short-term memory for pictures which is not statistically significant.

Conclusion: In the present study we have observed that males are having more short-term memory for numbers. Females are having more short-term memory for words and slightly more short-term memory for pictures. More study is required to study the dimorphism of the brain to understand the reason for these differences
\end{abstract}

Key words: Short-term memory

\section{Introduction}

Memory is of two types; short-term and longterm memory. Short-term memory is generally confined to less than twelve items and lasts only a few minutes. ${ }^{1}$ To the best of our knowledge, research on the relationship between gender and memory is in adequate in kerala. However, scientific experiments studying the relationship between attention and gender as well as memory and cognitive disorders were found. ${ }^{2}$ It was reported that attention-deficit hyperactivity disorder (ADHD) was shown to correlate to a deficit in working short-term memory. ${ }^{3}$ Females are expected to have better short-term memory than males. It was reported that males were better at remembering numbers and females were better at remembering words than numbers. ${ }^{4,5,6,7}$ Agneta et al.,( 2008) reported that throughout the life span, verbal episodicmemory tasks yield differences favoring women. In contrast, episodic-memory tasks requiring visuospatial processing result in differences favoring men. There are also sex differences favoring women on episodicmemory tasks requiring both verbal and visuospatial processing and on facerecognition tasks.8 Washburn (2005), 
reported that women were found to be more adaptive than males. ${ }^{9}$ Maki P M reported that estrogen may facilitate the automatic activation of verbal representations in memory. ${ }^{10}$ It is reported that Object-location memory is the only spatial task where female subjects have been shown to outperform males. ${ }^{11}$ Rui Guo et al., reported marked differences in spatial learning and memory between male and female $\mathrm{BALB} / \mathrm{c}$ mice (males performed better than females). ${ }^{12}$ These difference in short-term memory may be due to anatomical sex differences of brain . However these findings are inconsistent and initiate the need for future research in this aspect.

The present study was undertaken with the objective to observe whether there is a difference in short-term memory of males and females of Kerala and to create awareness among the healthy male and female to improve the quality of life.

\section{Materials and Methods Subjects}

The present study has been performed at Little Flower Medical Research Centre, Angamaly, Kerala, India. Twenty healthy males and twenty healthy females of Kerala with mean age $23+/-5$ were enrolled. The purpose and procedure of the study were explained to each subject. Written informed consent was taken from all the participants. Study protocol was approved by Institutional Ethics Committee of Little Flower Medical Research Centre, Angamaly.

In our study we have used a free- recall task of words, numbers and pictures in six sessions. ${ }^{13}$

At the beginning we have given a plain paper to all the subjects in which we have asked them to write their age, sex, and do they have any cognitive disorder or head injury. To test the short-term memory of the subjects, we planned our study in six sessions. First three sessions were prepared with ten words, numbers and pictures. In the first session we displayed a list of ten words. Ten words were carefully selected to ensure that they were unrelated. In second session we displayed ten random numbers and in third session we displayed ten pictures which are unrelated. We have asked the subjects to recall the displayed words, numbers and pictures. Numbers of the correct items recalled were measured.

In each session ten words, numbers and pictures were displayed to all the subjects for one minute and one minute break is given where words or numbers or pictures are not displayed and discussions was done with the subjects about the sports and politics to prevent them to recall the words. After this one minute break, in each session all the subjects were provided with one minute time to write the words, numbers and name of the pictures displayed on a paper. At the end of each session, we have collected the papers from the participants.

We have prepared last three sessions with twenty words, numbers and pictures in each session, where we displayed for two minutes and one minute break is given where we discussed about sports and college events with the subjects and in each session, immediately after one minute break subjects were asked to write the words, numbers and pictures displayed on a paper at the end of each session we have collected the papers.

\section{Data analysis}

The analysis of data is done by SPSS 20.0. 


\section{Results}

Table : 1 Mean values of free recall of words, numbers and pictures in six rounds

\begin{tabular}{|l|r|r|r|r|r|r|}
\hline Gender & Round1words & \multicolumn{1}{c|}{ Round2no } & \multicolumn{1}{c|}{ Round3pic } & \multicolumn{1}{c|}{ Round4words } & \multicolumn{1}{c|}{ Round5no } & \multicolumn{1}{c|}{ Round6pic } \\
\hline Male & $8 \pm 1$ & $9 \pm 1$ & $9 \pm 1$ & $14 \pm 2$ & $16 \pm 4$ & $18 \pm 2$ \\
\hline Female & $9 \pm 1$ & $7 \pm 2$ & $9 \pm 1$ & $16 \pm 3$ & $11 \pm 4$ & $17 \pm 2$ \\
\hline P Value & $<0.001$ & $<0.001$ & 0.699 & 0.024 & $<0.001$ & 0.295 \\
\hline
\end{tabular}

The analysis of data is presented in table: 1 . The mean free recall of words in round one in males is $8+/-1$ and in females $9+/-1$, which indicates that females are having more shortterm memory for words than males. This is statistically significant at 1 percent level of significance $(p<0.001)$. (Fig: 1$)$

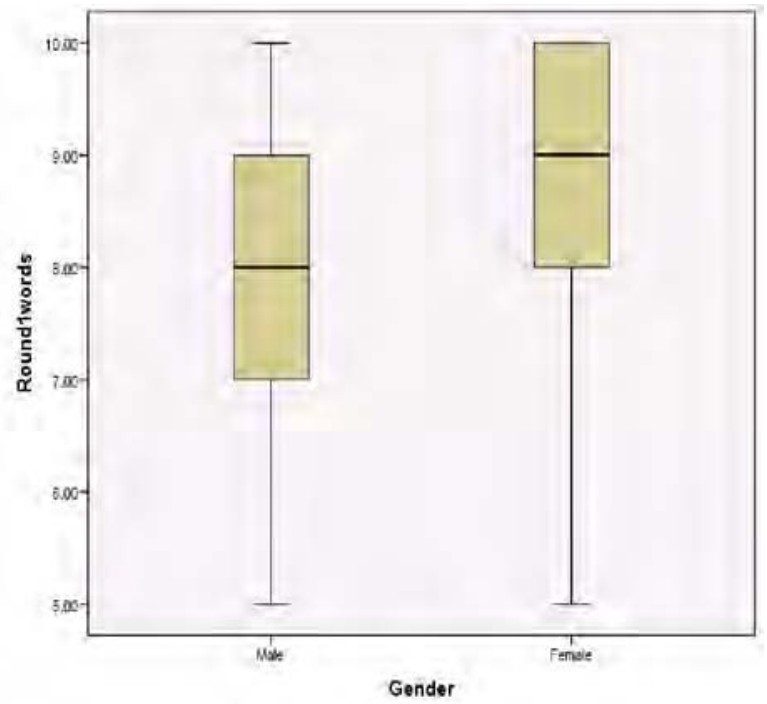

Fig:1 Boxplot diagram of free recall of words The mean free recall of numbers in round two in males is $9+/-1$ and in females $7+/-2$, which indicates that males are having more short-term memory for numbers than females. This is statistically significant at 1 percent level of significance $(p<0.001)$. (Fig: 2$)$

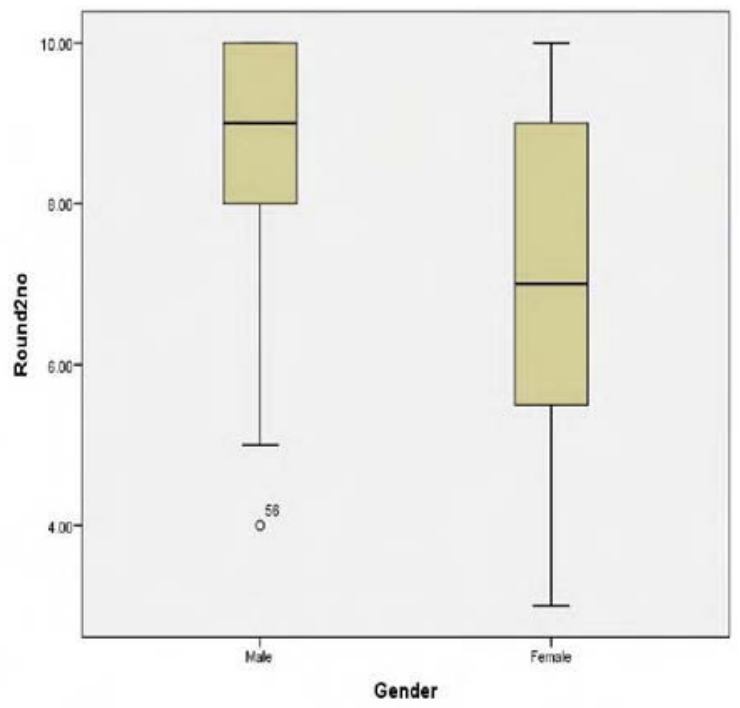

Fig: 2 Boxplot diagram of free recall of numbers.

The mean free recall of pictures in round three in males is $9+/-1$ and in females $9+/-$ 1 , which indicates that females has slightly more short-term memory for pictures than males. This is not statistically significant $(\mathrm{p}$ value is 0.699 ). ( Fig : 3)

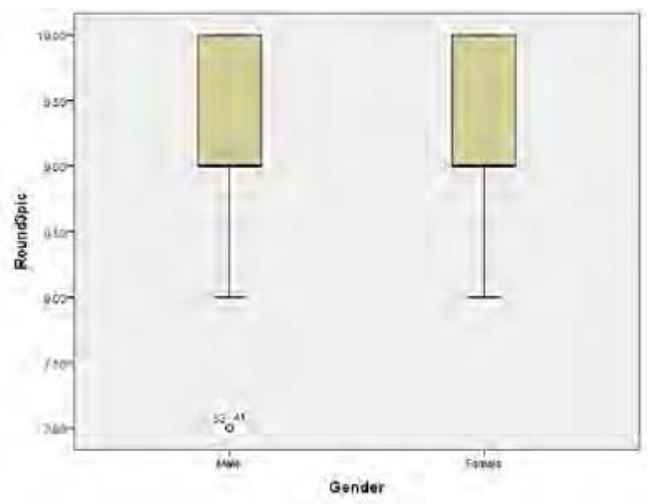

Fig: 3 Boxplot diagram of free recall of pictures 
The mean free recall of words in round four in males is $14+/-2$ and in females $16+/-3$, which indicates that females are having more short-term memory for words than males. This is statistically significant at 5 percent level of significance.

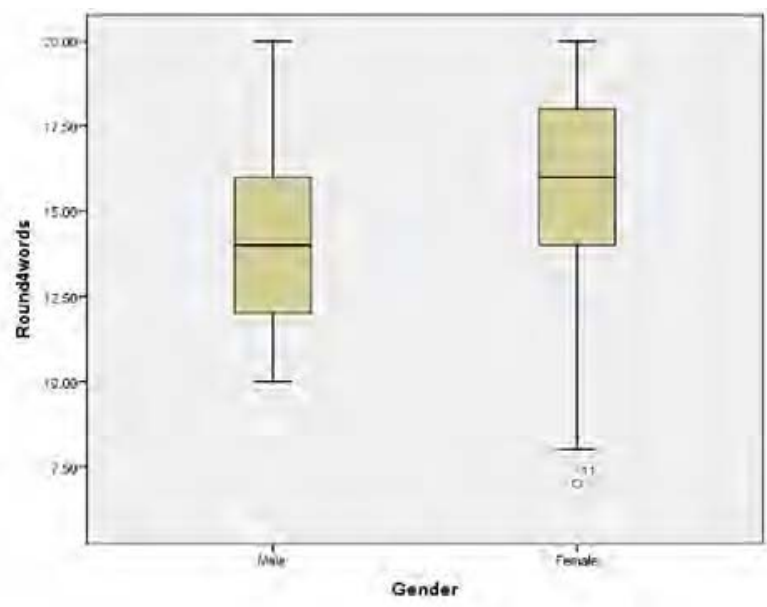

Fig: 4 Boxplot diagram of free recall of words.

The mean free recall of numbers in round five in males is $16+/-4$ and in females $11+/-4$, which indicates that males are having more short-term memory for numbers than females. This is statistically significant at 1 percent level of significance $(p<0.001)$.

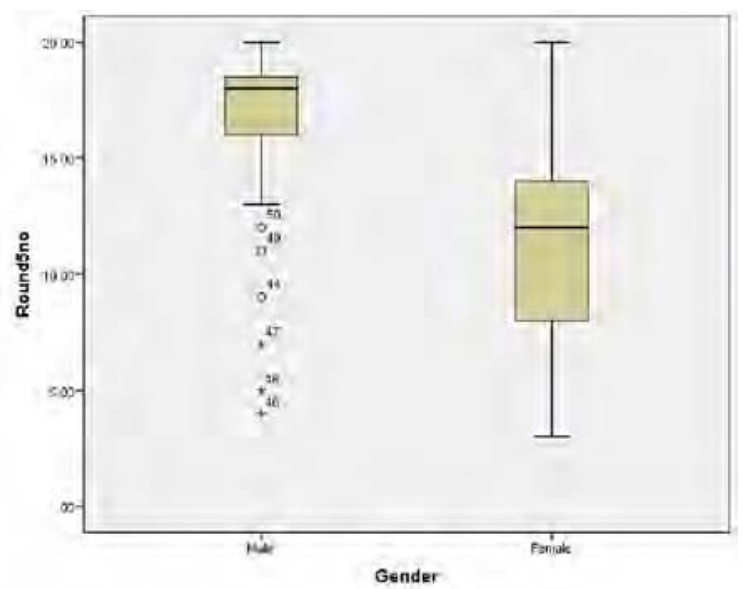

Fig: 5 Boxplot diagram of free recall of numbers The mean free recall of pictures in round six in males is $18+/-2$ and in females $17+/-2$, which indicates that females has slightly more short-term memory for pictures than males.
This is not statistically significant ( $p$ value is 0.295).

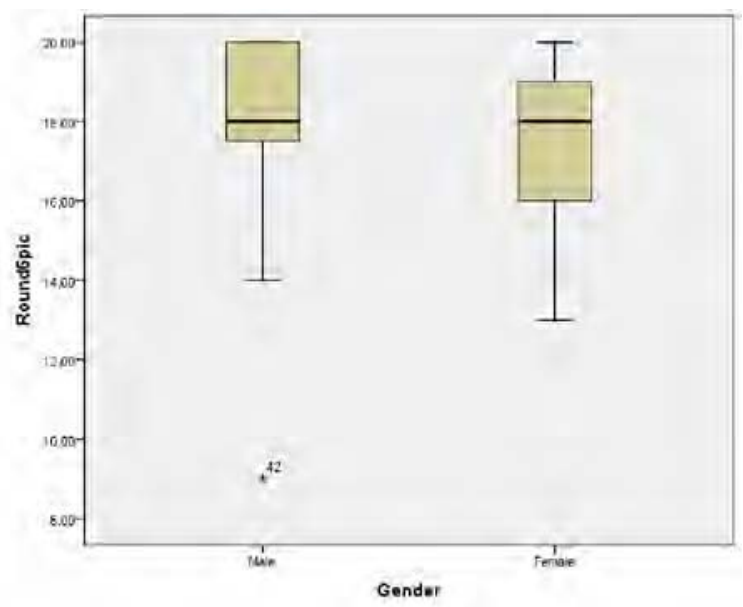

Fig: 6 Boxplot diagram of free recall of picture

\section{Discussion}

The results of the present study suggests that males are having more short-term memory for numbers and females are having more shortterm memory for words and slightly more short-term memory for pictures. Our study is supporting the research work of Terrence G. Horgan, who reported that under both directed- and incidental-learning conditions, they found that women recalled more accurately the information concerning the appearance of social targets than men. ${ }^{14}$ These difference in short-term memory in males and females may be due to anatomical sex differences of brain ${ }^{15,16}$ or due to effects of estrogen, as estrogen maintains verbal memory although the effect is modest. ${ }^{17}$ Estrogen may modulate prefrontal cortex and influences memory function, particularly working memory. ${ }^{18}$ However more study is needed to confirm this.

\section{Conclusion}

In the present study we have observed that males are having more short-term memory for numbers and females are having more short- 
term memory for words and slightly more short-term memory for pictures. More study is required to study the dimorphism of the brain to understand the reason for these differences.

\section{Acknowledgement}

We hereby acknowledge Dr. N.J. Antony, Professor Emeritus, department of physiology, Little Flower Institute of Medical Sciences and Research, Angamaly, Kerala for his valuable suggestions.

\section{References}

1. R.L. Bijlani and S.Manjunatha. Understanding medical physiology, India, Jaypee publications. Fourth edition; 99.

2. Lauren E. Banks. Gender Differences in ShortTerm Memory. Kennesaw State University.

3. Sinha.G . Training the brain. Scientific American. 2005 ; Vol.293: Issue 1: 66-68.

4. Laura Jennings, Timina Liu. The greatest rivalry of all time: Male vs female: Children vs adults: short-term memory. Burgmann Anglican School.

5. Physicians A.A. Memory loss with ageing: what's normal, what's not. Family doctor.org. 2010.

6. Witmer D. Teens from about.com. 2010.

7. Labkovsky E.B. Memory. Brain behavior optimization.com.

8. Agneta Herlitz, Jenny Rehnman. Sex differences in episodic memory. Current Directions in Psychological Science. February 2008; Vol. 17. no. 152-56.

9. Washburn, D. Individual differences in metacognitive responsiveness: Cognitive and personality correlates. Journal of general psychology; 2005; Vol. 132 : Issue 4: 446-461.

10. Maki PM, Rich JB, Rosenbaum RS. Implicit memory varies across the menstrual cycle: estrogen effects in young women. 2002; 40(5): 518-29.

11. Maartje De Goede, Albert Postma. Gender differences in memory for objects and their locations: A study on automatic verses controlled encoding and retrieval contexts. April 2008; Vol 66, Issue 3, 232-242.

12. Rui Guo, Na Liang, Fa-Dao Tai, Rui-Yong Wu, Gang Chang, Fen-Qin He, and Qin-Wei Yuan. Differences in Spatial Learning and Memory for Male and Female Mandarin Voles (Microtus mandarinus) and BALB/c Mice. Zoological Studies ; 2011; 50(1): 24-30.

13. Harness A, Jacot L, Scherf S, White A, Warnick JE. Sex differences in working memory._Psychol Rep. Aug 2008; 103(1): 214-8.

14. Terrence G. Horgan, Marianne Schmid Mast, Judith A. Hall, Jason D. Carter. Gender Differences in Memory for the Appearance of Others. Personality and social psychology bulletin. April 8, 2003; 185-196.

15. LS Allen, MF Richey, YM Chai and RA gorski. Sex differences in the corpus callosum of the living human being. The Journal of Neuroscience, April 1991; 11(4): 933 - 942.

16. Katherine M. Bishop and Douglas Wahlsten. Sex differences in the human corpus callousum: Myth or Reality. Neurosciences and behavioral reviews. 1997; Vol-21; No-5: 581-601.

17. Sherwin BB. Estrogenic effects on memory in women. Ann N Y Acad Sci. Nov 1994; 743: 213 -30 .

18. Sarah J. Duff, Elizabeth Hampson. A beneficial effect of estrogen on working memory in post menopausal women taking hormone replacement therapy. Hormones and behavior. December 2000; Vol 38; $262-276$.

Address of Correspondence: Dr.J.K.Mukkadan, Research Director, Little Flower Medical Research Centre, Angamaly,, Kerala, India., drmukkadan@sify.com 